\title{
CORTICAL FOLDING ON MEDIAL SURFACE OF FOETAL BRAIN AT DIFFERENT GESTATIONAL AGE
}

\author{
Gayatri. N *1, H.R.Sarada Sharma 2 . \\ *1 Associate Professor of Anatomy, MNR Medical College and Hospital, Sangareddy, Telangana, \\ India.
}

${ }^{2}$ Assistant Professor of Anatomy,MNR Medical College and Hospital, Sangareddy, Telangana, India.

\section{ABSTRACT}

Background: Cortical folding is a hallmark of many but not all mammalian brains. The degree of folding gradually increases with the size of brains in mammals but at different range between the families.Gyrification is a process which varies widely in mammals in early foetal and prenatal life.

Materials: This study was conducted on 100 dead foetuses in anatomy department, brought from the department of Obstetrics and gynaecology of MNR Medical College and Hospital.

Results: The brain surface is smooth up to 12 weeks, Cingulate sulcus appeared by $16-18$ weeks.Growth of adjoining lobes of brain make surface more convoluted with well-defined sulci and gyral pattern between 30-32 weeks.

Conclusion: Cortical folding is due to consequence of restricted space and rapid growth of brain with in the cranial cavity. There is no differences between male and female brains of same gestational age, with no obvious asymmetrical development of gyri on different lobes of brain.

KEY WORDS: Cortical folding, gyrfication, Gestational age, convolutions

Address for Correspondence: Dr. Gayatri. N, Associate Professor of Anatomy, MNR Medical College and Hospital, Sangareddy, Telangana, India. Mobile no: +919866084854 .

E-Mail: drgayatri1884@gmail.com

Access this Article online

Quick Response code

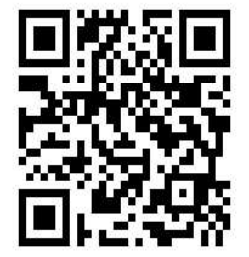

DOI: $10.16965 /$ ijar.2019.246

Journal Information

International Journal of Anatomy and Research

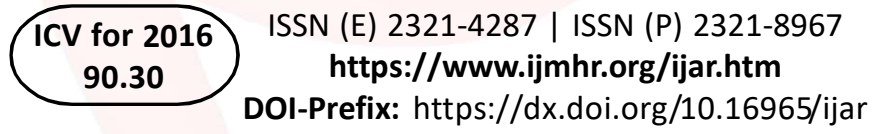

Article Information

Received: 07 Jun 2019

Peer Review: 07 Jun 2019

Revised: None
Accepted: 08 Jul 2019

Published (O): 05 Aug 2019

Published (P): 05 Aug 2019

\section{INTRODUCTION}

The surface of the human brain cortex is made up of many convoluted folds separated by spaces known as sulci. The classification of these sulci is an important step in many neuroimaging studies, which seek to analyse morphological changes in regions of interest on the cortex [1].

Brain maturation is an organised, predetermined pattern that correlates with the function of thenew-born or infant performs. It develops rapidly between 5 th weeks to the end of 12 th week of intrauterine life at various stages of development [2]. Gyration is a phenomenon occurring late during foetaldevelopment. It goes on to the end pregnancy \& even later after birth. Sulci appear as groove on the surface of brain called as primary sulci Gyration proceeds with formation of side branches from primary sulci called as secondary sulci which branch to form tertiary sulci .Time of appearance of different sulci is so precise that gyration is considered to be reliable estimate of foetal age and brain maturation [3]. 
Knowledge of it guides us regarding morphological \& functional changes of developing brain in terms of treatment \& protection of vital structures [4].

Hence the present study was conducted to provide more information regarding the appearance and description of sulci \& gyri on medial surface human foetal brain.

\section{MATERIALS AND METHODS}

The present study was conducted in MNR Medical College and Hospital, Sangareddy100 dead foetuses/stillbirth of various cause are collected from department of Obstetrics and gynaecology .Foetal brain is embalmed with concentrated $40 \%$ formalin and dissected after 48 hours Gestational age of the dead foetuses is calculated by Crown - rump length, biparietal diameter, Head circumference, abdominal circumference [5] and grouped into 5 groups with an interval of 6 weeks.

Table 1: Distribution of number foetuses into 5 groups according to sex.

\begin{tabular}{|c|c|c|c|c|}
\hline Group & $\begin{array}{c}\text { Gestational } \\
\text { age (weeks) }\end{array}$ & Female & Male & $\begin{array}{c}\text { Total no of } \\
\text { foetuses } \\
(\mathbf{n})=100\end{array}$ \\
\hline Group -1 & Dec-18 & 12 & 11 & 23 \\
\hline Group -2 & $>18-24$ & 8 & 14 & 22 \\
\hline Group -3 & $>24-30$ & 10 & 12 & 22 \\
\hline Group -4 & $>30-36$ & 8 & 10 & 18 \\
\hline Group- 5 & $>36-40$ & 7 & 8 & 15 \\
\hline
\end{tabular}

Brain is removed with dissection method [6]. Skin of the scalp is reflected in four flaps, later followed by reflecting the membranous vault bones again in four flaps, dura is cut and opened in four flaps. The falxcerebri is cut from crista galli and pulled back with one hand while the palm of other hand supports the brain from posterior aspect. Frontal lobes are gently separated and lifted back from anterior cranial fossa, olfactory bulbs are separated from cribriform plate of ethmoid, and later optic nerves are cut close to optic foramina. Later macroscopically for description of sulci.

\section{RESULTS}

- Callosal sulcus (CoS) - appears and separate corpus callosum from overlying cingulate gyrus by12-14 wks.

- Cingulate sulcus (CiS)- appear as parallel sulcus and become recognizable with it gyri by 16-18 wks.

- Parieto -occipital sulcus (POS) - appear as a prominent sulcus and clearly separates the primitive occipital lobe from the parietal lobe between 16-18 wks.

Fig. 1: Showing the Brain Surface in GROUP-1 (12-18wks).

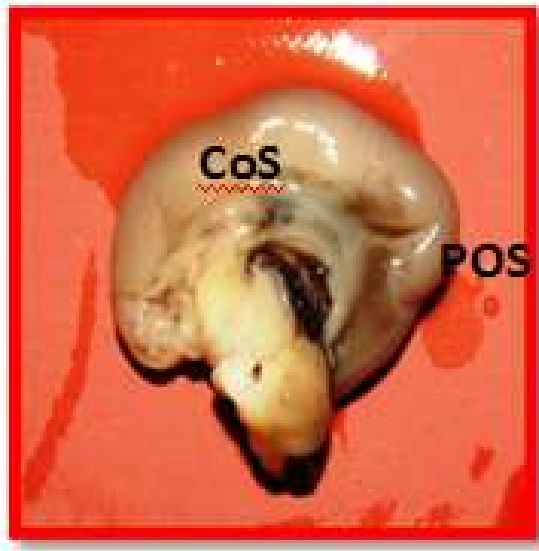

Fig. 2: Showing the Brain Surface in GROUP- 2 (>1824wks).

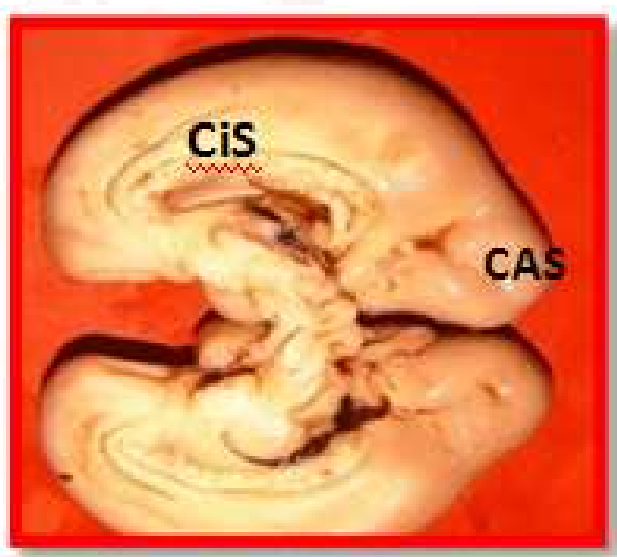

Calcarine sulcus (CAS) - appear as definite sulcus and joins with parieto-occipital sulcus by 18-20 wks.

Fig. 3: Showing the Brain Surface in GROUP-3 (>24- 30wks).

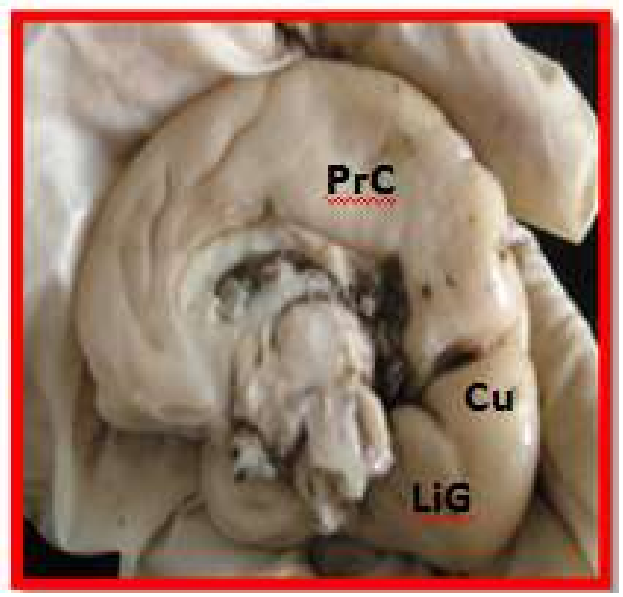

- Lingual gyrus (LiG) and Cuneus (Cu) - appear between 24-26wks. 
Fig. 4: Showing the Brain Surface in GROUP-4 (>30-36weeks).

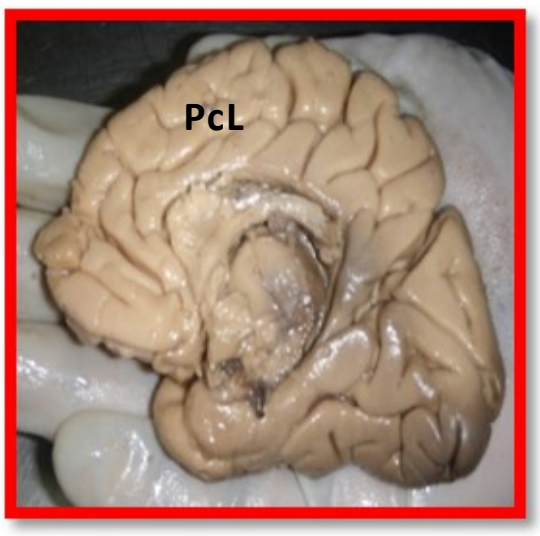

Paracentral lobule (PCL) - appears between 30-32wks.

\section{DISCUSSION}

Brain surface is smooth up to 12 weeksand is supported by the findings of Henry Gray [7] but V.I.Savelev observed smooth brain at 16 weeks [8]

Table 2: Comparison of appearance gyri in present study with other studies.

\begin{tabular}{|c|c|c|}
\hline Characteristics & Present study & Chi et al, 1977 [9]. \\
\hline No of foetuses & 100 & 107 \\
\hline Gestational age in weeks & $12-40$ & $10-44$ \\
\hline Medial surface(wks) & & \\
Cingulate gyrus & $16-18$ & 18 \\
Paracentral lobule & $30-32$ & 35 \\
Cuneus & $24-26$ & 27 \\
Lingual gyrus & $24-26$ & 27 \\
\hline
\end{tabular}

Table 3: Comparison of appearancesulci in present study with other studies.

\begin{tabular}{|c|c|c|c|}
\hline Characteristics & Present study & Chi et al, 1977. & Nisikuni, 2006 [10]. \\
\hline No of foetuses & 100 & 107 & 207 \\
\hline Gestational age in weeks & $12-40$ & $9-44$ & $12-40$ \\
\hline Medial surface (wks). & & & \\
Callosal sulcus. & $12-14$ & 14 & 12 \\
Cingulate sulcus. & $16-18$ & 18 & 19 \\
Parietooccipital sulcus. & $16-18$ & 16 & 19 \\
Calcarine sulcus. & $18-20$ & 16 & 17 \\
Secondary sulcus(wks) & $36-38$ & 40 & 38 \\
\hline
\end{tabular}

\section{CONCLUSION}

Present study was carried on 100 dead foetal brains, initially brain surface is smooth upto 12-16 weeks on medial surface. Cingulate sulcus appeared by 16-18weeks.

There is no asymmetrical development of sulci and gyri on different lobes of the foetal brain. Convoluted pattern on medial surface became more prominent during 30-32 weeks.

There is no difference between male and female foetal brain of same gestational age.
Fig. 5: Showing the Brain Surface in GROUP-5 (>36-40wks).

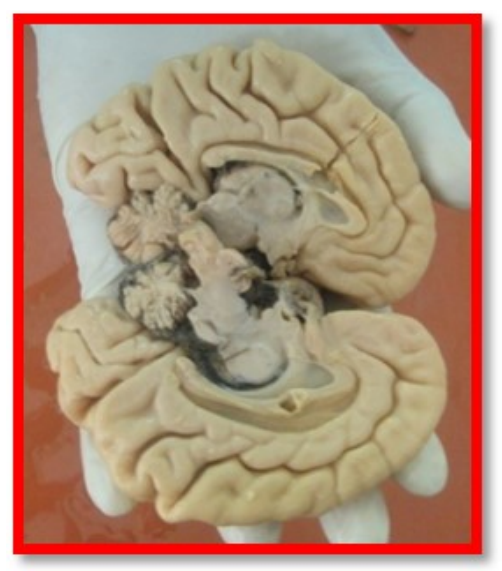

- Secondary sulci \& gyri - appear by $36-38$ wks

\section{ACKNOWLEDGEMENTS}

I would like to acknowledge the support I got from my colleagues Department of Anatomy, MNRMedical College and Hospital,Sangareddy.

\section{Conflicts of Interests: None}

\section{REFERENCES}

[1]. K. Behnke, M. Rettmann, D. Pham, D. Shen, S. Resnick, et al. "Automatic classification of sulcal regions of the human brain cortex using pattern recognition," in Proc. SPIE's Medical Imaging, San Diego, CA.2003;Feb. 15-20.

[2]. Keith. I. Moore. The developing human clinical oriented embryology.2008;396-404

[3]. Catherine Garel, Emmanuel Chantrel et al. Fetal cerebral cortex: Normal gestational landmarks identified using prenatal MR imaging; American Journal of Neuroradiology. 2001; 22:184-189.

[4]. Gregory E. Antonio, Winnie C.W.Chu, David K.W.Yeung, Anil T Ahuja. Imaging of the developing brain; Neuroembrology\& aging. 2008; 5:23-31.

[5]. Dr.Hughey: Military Obstetrics \&Gynecology. Brookside Associates Medical Education Division. 2009; 395.

[6]. G.J. Romanes. Cunningham Manual of Practical Anatomy, Head and neck and brain.1986; 39:43-44.

[7]. Development of Nervous system. Henry Gray's 39th edition, London; Elsevier Churchill \& Livingstone P, 2005:266.

[8]. V. I. Savel'ev. Variability of sulci and gyri in the inferior parietal Region of the human during ontogeny. Neuroscience \& Behavioural Physiology.1984; 14(1):60-63.

[9]. Chi JG, Dooling EC, Gilles FH. Gyral development of the human Brain. Ann Neurol.1977; 1:86-93.

[10]. A. Afif, R. Bouvier, A. Bunerd, J. Trouillas and P. Mertens: Development of the human fetal insular cortex: study of the gyration from 13 to 28 gestational weeks. Brain Structure and Function.2010; 212(3-4):335346. 